\title{
So versorgen Sie eingewachsene Nägel
}

VON A. SCHUH, W. HÖNLE

\begin{abstract}
Ein eingewachsener Zehennagel verursacht heftige Schmerzen und muss in jedem Fall behandelt werden: Oft ist der Nagelfalz entzündet und beginnt zu eitern; evtl. hat sich bereits Granulationsgewebe gebildet, das den Nagel überwuchert. Lesen Sie, welche Therapie langfristig für Beschwerdefreiheit sorgt.
\end{abstract}

- Die Nagelmatrix erstreckt sich in proximaler Richtung bis etwa $5 \mathrm{~mm}$ vor das Nagelbett und produziert Nagelsubstanz. Diese wächst etwa $0,1 \mathrm{~mm}$ täglich ins Nagelbett vorwärts. Das Wachstum kann gestört werden durch

- Infektionen,

- Durchblutungsstörungen,

- Verletzungen,

- Schuhdruck oder

- falsche Fußpflege.

\section{Falsche Fußpflege - die häufigste} Ursache für eingewachsene Nägel Zehennägel sollten nicht gebogen geschnitten werden (Abb. 1, 2)! Die Folge falschen Schneidens ist eine Ernährungsstörung mit trophischen Nagelveränderungen oder eine Verhornung des seitlichen Nagelbetts mit zunehmender Abhebung des Nagels (Unguis incarnatus).

Seitlicher Druck gegen den Nagelfalz/den Nagel im Schuh führt zu einer Entzündung des Nagelfalzes. Eine Fehlstellung der Großzehe im Sinne eines Hallux valgus kann dies begünstigen.

Schmerzen können durch lokalen Druck auf die Zehe, z. B. durch das Tragen von engen Schuhen, hervorgerufen werden. Der Nagelrand ist nicht mehr zu sehen, der hypertrophierte, gerötete Nagelfalz überdeckt den Nagel, auf Druck tritt häufig Sekret aus; infolgedessen können Infektionen auftreten.

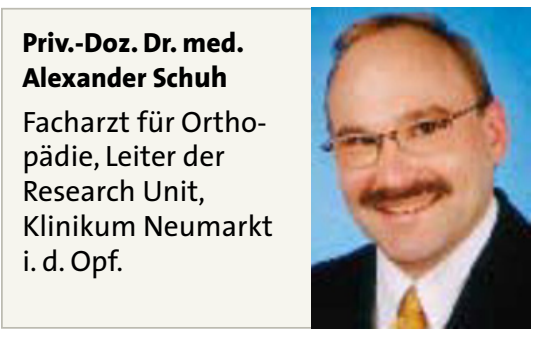

Nagelklammer oder Emmert-Plastik? Der Druck des Schuhwerks muss beim eingewachsenen Großzehennagel vermieden werden. Zur konservativen Therapie kommen Nagelklammern infrage (Abb. 3), um den seitlichen $\mathrm{Na}$ gelkanten das Auswachsen zu ermöglichen (ergänzend Betaisodona-Fußbäder, Salbenumschläge).

Bei Therapieresistenz ist die operative Versorgung („Emmert-Plastik“) angezeigt. Hier wird am eingewachsenen Nagelrand eine keilförmige Exzision durch Nagelbett und -matrix bis zum Knochen durchgeführt. Durch diesen Eingriff werden die Patienten i.d.R. anhaltend beschwerdefrei (Abb. 4).

\section{Literatur bei den Verfassern}

Für die Verfasser:

Priv.-Doz. Dr. med. habil. Alexander Schuh Research Unit, Klinikum Neumarkt

Nürnberger Str. 12, D-92318 Neumarkt i.d.OPf. E-Mail:Alexander.Schuh@klinikum.neumarkt.de

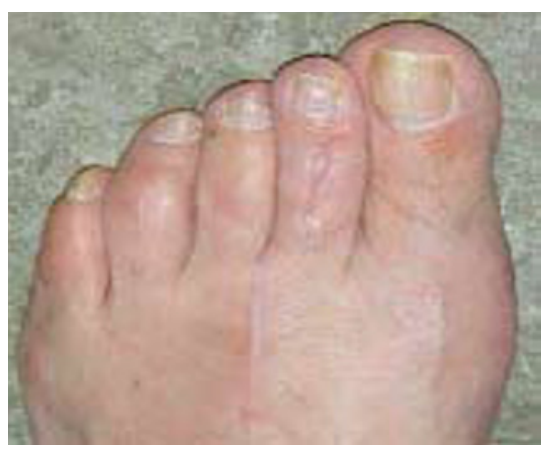

Abb. 1 Korrekt geschnittener Großzehennagel.

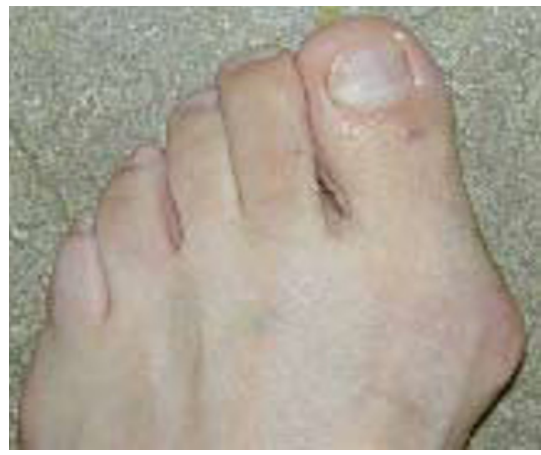

Abb. 2 Wird der Großzehennagel falsch (gebogen) geschnitten, kann er einwachsen.

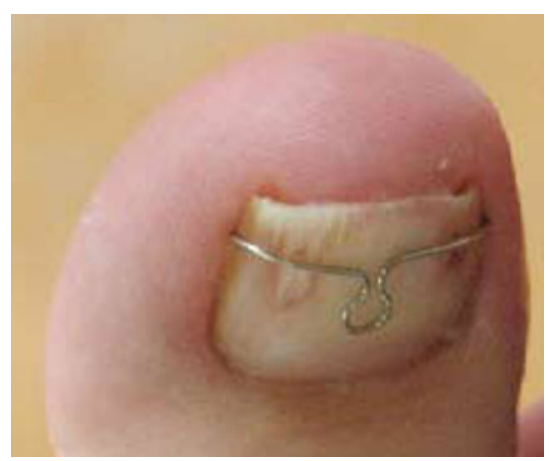

Abb. 3 Versorgung eines eingewachsenen Großzehennagels mit einer Klammer.

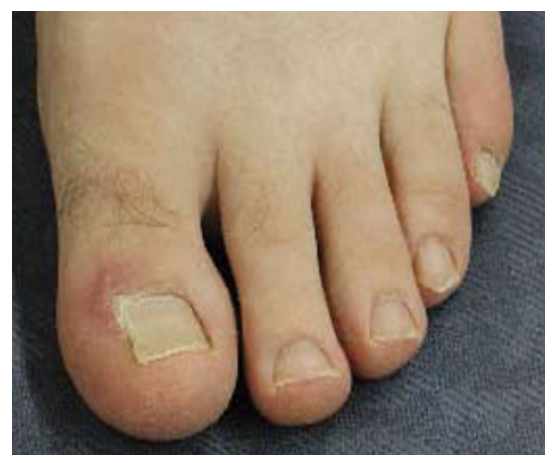

Abb. 4 Nach der Emmert-Plastik ist der Großzehennagel schmäler, wächst jedoch nicht mehr ein; der Patient bleibt meist anhaltend beschwerdefrei. 